\section{Bertrand Guidet Julian Bion}

\title{
Night thoughts
}

Received: 21 August 2014

Accepted: 22 August 2014

Published online: 3 September 2014

(C) Springer-Verlag Berlin Heidelberg and ESICM 2014

B. Guidet $(\bowtie)$

Assistance Publique-Hôpitaux de Paris, Hôpital Saint-Antoine, service de réanimation médicale, F-75012 Paris, France

e-mail: bertrand.guidet@sat.aphp.fr

B. Guidet

Sorbonne Universités, UPMC Univ Paris 06, UMR_S 1136, Institut Pierre Louis d'Epidémiologie et de Santé Publique, F-75013 Paris, France

B. Guidet

INSERM, UMR_S 1136, Institut Pierre Louis d'Epidémiologie et de Santé Publique, F-75013 Paris, France

J. Bion

University of Birmingham, Birmingham, UK

Transitions in and out of the intensive care unit (ICU) are major steps in the trajectory of hospitalised critically ill patients, for whom accurate clinical assessment, selection of the correct level of care, and maintenance of continuity of care are fundamental determinants of outcome. Out-ofhours $(\mathrm{OOH})$ discharge is known to be associated with adverse outcomes for patients, and is now being used as a quality indicator in the UK and USA. Leaving aside for one moment what 'out-of-hours' might mean in health services ostensibly offering $24 \mathrm{~h}$ care 7 days a week, it would seem reasonable to hypothesise that, as health services improve with time, secular trends might demonstrate a reduction in frequency and in adverse outcomes of being discharged at night from an ICU to an ordinary ward.
However, in this issue of Intensive Care Medicine, Gantner and colleagues present an analysis of the ANZICS case mix program database which shows that discharge out-of-hours (taken as 1800-0600 hours) from ICUs in Australia and New Zealand is associated with a markedly elevated adjusted risk of death, and that neither the risk nor the rate of $\mathrm{OOH}$ discharge (around $15 \%$ ) has changed over the 8-year study period (2005-2012) [1]. Risk was higher for $\mathrm{OOH}$ discharge in private hospitals, and applied to all diagnostic groups examined, including post-cardiac surgical patients. Patients discharged $\mathrm{OOH}$ tended to have more severe illness at ICU admission, and longer ICU stays. These patients are more likely to have had prior limited physiological reserve, or to have sustained substantial loss of physical capacity during their ICU stay, and therefore to be at higher risk following discharge. The odds ratio for mortality was 1.34 which is very similar to previous studies in Australia: 1.7 [2], 1.63 [3]; in Australia and New Zealand: 1.4 [4]; in the UK: 1.46 [5]; in Canada: 1.22 [6], 1.2 [7]; and in France: 1.56 [8]. The consistency of the impact of night discharge on outcome is remarkable since it is observed across countries with different healthcare systems and funding.

Why are the nights dangerous? There are several potential explanations. Given that nighttime discharge is unlikely to seen as desirable, it is almost certainly a surrogate measure of premature discharge in the setting of continuing referrals of critically ill patients to an already full ICU. The principle of distributive justice [9] encourages the intensivist to exchange the "less severe" patient for one who is more acutely ill; the unspoken assumption is that delayed admission (or the inconvenience of providing off-site intensive care support) is more disadvantageous than the risks of premature discharge. This decision disadvantages the discharged patient, the patient's family and, in the long term, the ICU team. Gantner and colleagues report that, during the study period, the proportion of discharges by hour of day 
remained constant, but the absolute number of ICU discharges increased by $38.5 \%$. It is therefore reasonable to assume that nighttime discharge is an expression of rationing, with increased referrals to intensive care offsetting any increase in resources.

The second possible explanation is poor decisionmaking by the medical staff. Admission and discharge decisions should be taken by the senior ICU physician on duty, not by trainees or non-intensivists. As ICUs in Australia and New Zealand are managed by intensivists (the so-called 'closed model'), one has to assume that the discharge decisions were taken in the full knowledge of potentially adverse outcomes. This suggests the opportunity for undertaking fieldwork to understand the nature of senior decision-making at the time of admission and discharge, and prospective studies of decision-support models for readiness for discharge $[10,11]$.

A third possibility is that nighttime discharge is accompanied by poor handover procedures and lapses in communication. Transitions in care are known to be associated with discontinuities in treatment [12] and an increased risk of adverse events. As nighttime hospital staffing is a fraction of those present during the day, discharged patients may be reviewed cursorily, or not at all, by junior medical staff preoccupied with other emergency duties until their shift ends.

Finally, suboptimal care in ordinary wards is a likely contributor to post-ICU complications. In the Western world, ICU populations contain an increasing proportion of the frail elderly, whose reserves are so compromised that they cannot cope with the reduction in basic nursing care associated with ward care. Intensive care specialists may fail to recognise that the patient they are about to release from the ICU suffers from nocturnal delirium, is so weak she cannot sit up in bed unaided, reach a nurse call button, or hold a glass of water to her lips, and still has a low-grade inflammatory response slowing the progression of tissue healing. In the ICU, these problems are scarcely noticed because the environment is configured to deal with them, but in the ordinary wards they become major barriers to recovery. Intermediate care facilities [13] and expert ward support in the form of outreach care or rapid response teams [14] may help to mitigate the ward environment, but the real challenge lies in reconfiguring the entire hospital system so that it provides safe care for all acutely ill patients regardless of location [15].

What lessons can we learn from the growing literature on nighttime discharge from the ICU? We make some suggestions for minimising both the frequency and the impact of $\mathrm{OOH}$ discharges in Table 1. Reduction of nighttime discharge rates and prevention of adverse consequences for our patients is not merely an ICU
Table 1 Approaches to minimising the frequency and impact of $\mathrm{OOH}$ discharges from ICU

1. Patient level

a. Discharge decisions to be made only by the intensive care specialist

b. Early identification of patient readiness for discharge to permit forward planning

c. Daily assessment of patient reserve, dependence and therapeutic workload

d. Critical incident reporting for unplanned nighttime discharges 2. ICU level

a. Registry of out-of-hours discharges and delayed admissions

b. Formalised hand-over procedures

c. Integration of step-down (high-dependency) units with the ICU

d. Modification of the nurse:patient ratio instead of transferring the patient to another location

3. Hospital level

a. Active integrated bed management linking intensive care to other departments

b. Electronic patient records across the hospital

c. $24 \mathrm{~h}$ outreach care

d. Vital signs early warning systems to enable prompt detection of impending critical illness

e. Anticipation of need for ICU admission (planned or emergency surgery)

f. Anticipation of seasonal effects (i.e. influenza)

4. Health policy and ethics

a. National registries and case mix programmes to monitor ICU performance

b. Discussions with ethicists and the public on the impact of rationing intensive care resources

issue, it is a challenge for hospital management, for health policy makers, and for the public. Local and national data on nighttime discharges will lend weight to discussions with funders, and should be incorporated in discussions about the wide international variations in intensive care resources [16]. Is the lack of ICU beds for the next admission a consequence of unwillingness to confront end-of-life care issues while continuing futile care? Do we audit our own individual discharge decision-making in terms of post-ICU deaths and ICU readmissions, and are those decisions better or worse than predictive instruments $[10,11,17]$, which might in time become incorporated in electronic clinical decision support systems? Given the impact on mortality, we should record all unplanned nighttime discharges as critical incidents.

The eighteenth century poet Edward Young's major work 'Night Thoughts' describes how rapidly life and opportunity escape our grasp. It is our duty as intensivists to minimise this adverse effect on our patients. If we had at our disposal a drug which could reduce mortality by 20-50 \%, we would all be using it. Avoiding nighttime discharge is that drug. 


\section{References}

1. Gantner D, Farley KJ, Bailey M, Huckson S, Hicks P, Pilcher D (2014) Mortality related to after-hours discharge from intensive care in Australia and New Zealand, 2005-2012. Intensive Care Med. doi: 10.1007/s00134-014-3438-x

2. Duke GJ, Green JV, Briedis JH (2004) Night-shift discharges from intensive care unit increases the mortality-risk of ICU survivors. Anaeth Intensive Care 32:697-701

3. Tobin AE, Santamaria JD (2006) Afterhours discharges from intensive care are associated with increased mortality.

Med J Aust 184:334-337

4. Pilcher DV, Duke GJ, George C, Bailey C, Hart G (2007) After-hours discharge from intensive care increases the risk of readmission and death. Anaesth Intensive Care 35:477-485

5. Golfrad C, Rowan K (2000) Consequences of discharges from intensive care at night. Lancet 355:1138-1142

6. Priestap FA, Martin CM (2006) Impact of intensive care unit discharge time on patient outcome. Crit Care Med 34:2946-2951
7. Laupland KB, Shahpori R, Kirkpatrick AW, Stelfox HT (2008) Hospital mortality among adults admitted to and discharged from intensive care on weekends and evenings. J Crit Care 23:317-324

8. Laupland KB, Misset B, Souweine B et al (2011) Mortality associated with timing of admission to and discharge from ICU: a retrospective cohort study. BMC Health Serv Res 11:321

9. McMillan J, Hope T (2010) Justicebased obligations in intensive care. Lancet 375:1156-1157

10. Badawi O, Breslow MJ (2012) Readmissions and death after ICU discharge: development and validation of two predictive models. PloS ONE 7:e48758

11. Hosein FS, Bobrovitz N, Berthelot S, Zygun D, Ghali WA, Stelfox HT (2013) A systematic review of tools for predicting severe adverse events following patient discharge from intensive care units. Crit Care 17:R102

12. Bell CM, Brener SS, Gunraj N et al (2011) Association of ICU or hospital admission with unintentional discontinuation of medications for chronic diseases. JAMA 306:840-847
13. Hutchings A, Durand MA, Grieve R et al (2009) Evaluation of modernization of adult critical care services in England: time series and cost effectiveness analysis. BMJ 339:b4353

14. Ball C, Kirkby M, Williams S (2003) Effect of the critical care outreach team on patient survival to discharge from hospital and readmission to critical care: non-randomised population based study. Br Med J 327:1014

15. Future Hospital: Caring for medical patients. Future Hospital Commission. Royal College of Physicians, London 2013. https://www.rcplondon.ac.uk/ projects/future-hospital-commission

16. Rhodes A, Ferdinande $\mathrm{P}$, Flaatten $\mathrm{H}$, Guidet B, Metnitz PG, Moreno RP (2012) The variability of critical care beds numbers in Europe. Intensive Care Med 38:1647-1653

17. Moreno R, Miranda DR, Matos R, Fevereiro T (2001) Mortality after discharge from intensive care: the impact of organ system failure and nursing workload use at discharge. Intensive Care Med 27:999-1004 